\title{
O NUDGE NO DESIGN DE CONTEÚDO NO APLICATIVO DE IDIOMAS DUOLINGO
}

\section{Dados dos Autores}

Kleiton Luiz Nascimento Reis

Doutorando, Universidade Federal de Santa Catarina (UFSC), https://orcid.org/0000-0002-0355$\underline{7045}$, kleitonluiz.reis@gmail.com

Maria José Baldessar

Doutora, Universidade Federal de Santa Catarina (UFSC), https://orcid.org/0000-0001-8971-4576, mbaldessar@gmail.com

Adilson Albuquerque

Mestrando, Universidade Federal de Santa Catarina (UFSC), albuquerque.filosofo@gmail.com

Karoline de Macedo Santos

Mestranda, Universidade Federal de Santa Catarina (UFSC), karoline.contato@gmail.com

\section{RESUMO}

Objetivo: O presente artigo tem por objetivo identificar os elementos nudges utilizados no aplicativo de ensino de idiomas Duolingo para engajar os usuários.

Design/Metodologia/Abordagem: Para tanto, serão discutidos neste artigo os conceitos de design de conteúdo, arquitetura da escolha e nudges, para a compreensão da importância do elemento nudge para o engajamento dos alunos tendo como referência autores como Afify (2018), Bieging \& Busarello (2014), Silva (2007) e Thaler (2019). Para análise foi feita a coleta de dados no 
aplicativo Duolingo para, então, fazer os apontamentos necessários para atingir o objetivo proposto neste trabalho.

Resultados: Ao final da análise, foi possível perceber que o aplicativo utiliza elementos nudges desde o cadastro para prender a atenção do leitor e fazê-lo iniciar seu percurso de aprendizado, e durante o uso do aplicativo faz uso de diversos elementos nudges em vários momentos para manter o usuário engajado.

Palavras-chave: nudges. Duolingo. engajar usuários.

\title{
NUDGE IN CONTENT DESIGN IN DUOLINGO LANGUAGE APPLICATION
}

\begin{abstract}
Goal: This article aims to identify the nudge elements used in the Duolingo language learning app to engage users.

Design / Methodology / Approach: In order to achieve this goal, the concepts of content design, choice architecture and nudges will be discussed in this article, to understand the importance of the nudge element for student engagement, with authors such as Afify (2018), Bieging \& Busarello (2014), Silva (2007) and Thaler (2019). For analysis, data were collected in the Duolingo application to make the necessary notes to achieve the objective proposed in this work.

Results: At the end of the analysis, it was possible to notice that the application uses nudge elements from the register to capture the reader's attention and start their learning path, and while using the application makes use of several nudge elements at various times to maintain the engaged user.
\end{abstract}

Keywords: nudges; Duolingo; engage user. 


\section{INTRODUÇÃO}

O desenvolvimento das Tecnologias da Informação e Comunicação (TIC) consolidaram uma rede de conexões globais, dinâmicas e de fácil interação, provocando uma transformação no modo de viver, nas relações sociais, no mundo do trabalho, lazer e, nas práticas de ensinar, aprender e produzir conhecimento. No ensino propiciou um melhor desenvolvimento da educação a distância - EAD, englobando as diversas faixas-etárias, sociais e econômicas, com o surgimento de formas pedagógicas visando abranger os grupos que necessitam de aperfeiçoamento e capacitação profissional. Nesses grupos, encontram-se profissionais, que limitados pelo espaço geográfico, pelo tempo e outros fatores que tornam impossível a sua presença em uma sala de aula, buscam o ensino EAD como forma de continuar seu processo educacional. Para suprir essa necessidade, um dos caminhos são os chamados cursos autoinstrucionais, entendidos como aqueles que visam garantir a autonomia e independência do indivíduo, a partir de um desenho autoexplicativo, que abordem temáticas de maneira simples e objetiva, sem a participação direta de professores e tutores.

O grande desafio que se coloca é como possibilitar que esse processo possa acontecer de maneira criativa e ajustadas à realidade do indivíduo através de diferentes meios com o intuito de elevar os níveis motivacionais e de engajamento com o propósito de proporcionar experiências mais efetivas e relevantes ao sujeito de maneira que possa criar condições para que se torne um espaço de interatividade, ainda que em um ambiente marcadamente autônomo. Uma das possibilidades que se apresentam é a utilização dos nudges para a construção da arquitetura da escolha. Esse sistema apropria-se de elementos motivacionais (dinâmicas, mecânicas e componentes) para aplicação em diferentes contextos. Por isso é importante ressaltar que:

Esse $n u d g e$, na nossa concepção, é um estímulo, um empurrãozinho, um cutucão: É qualquer aspecto da arquitetura de escolhas capaz de mudar o comportamento das pessoas de forma previsível sem vetar qualquer opção e sem nenhuma mudança significativa em seus incentivos econômicos (Thaler, 2019, p. 15)

É uma nova via que busca facilitar a aprendizagem, a comunicação, a disseminação e a criação do conhecimento, uma vez que tem a capacidade de comprometer seus participantes no caminho que pretendem seguir. A criação dos ambientes e artefatos que exploram os nudges são complexos e exigem um trabalho interdisciplinar com o envolvimento de profissionais das diferentes áreas e saberes. 
Dentro desse sistema é importante criar nudges que possuam maior probabilidade em ajudar o aluno e não em prejudicar. Outro ponto a ser levado em consideração é que para esse "empurrão" acontecer ele precisa possuir um baixo custo para ser considerado um nudge.

Por conta disso, empresas e organizações de diferentes setores têm utilizado essas ferramentas alternativas para encorajar pessoas a adotarem determinados comportamentos, com o intuito de familiarizar-se com as novas tecnologias, agilizarem os processos de aprendizagem e a tomada de decisão. Com isso, as formas cognitivas que o indivíduo aprende, percebe e se relaciona com o mundo, passa a acontecer de maneira criativa e ajustadas à sua realidade através de diferentes meios com o intuito de elevar os níveis motivacionais e de engajamento dos indivíduos com o propósito de proporcionar experiências mais efetivas e relevantes ao sujeito. A exploração por diferentes e criativas formas torna-se interessante porque elas têm o poder de integrar e motivar os agentes nos amplos e diversos contextos de aprendizagem tornando-a mais significativa e a arquitetura da escolha faz muito bem esse papel.

Diante desse cenário, este trabalho tem por objetivo identificar os elementos nudges utilizados no aplicativo de ensino de idiomas Duolingo para engajar os usuários. Para alcançar esse objetivo, foi realizada uma investigação de abordagem qualitativa, adequada quando se pretende explorar aspectos subjetivos de um tema de estudo (DUARTE, 2006).

Este estudo foi dividido em duas etapas. Na primeira, o procedimento utilizado foi o levantamento bibliográfico, para compreender melhor os constructos de design de conteúdo, arquitetura da escolha e nudges, e, assim, a importância do elemento nudge para o engajamento dos alunos no curso. Na segunda etapa, o procedimento adotado foi a indicação dos elementos que funcionam como nudges no sistema avaliado, a partir do aporte teórico adotado na etapa anterior.

\section{DESIGN DE CONTEÚDO}

O conteúdo é elemento fundamental quando o assunto é educação a distância, principalmente em cursos autoinstrucionais, já que não há a presença do professor ou de um tutor. Nesse contexto, o design de conteúdo é a área responsável pela organização da informação e como ela é apresentada ao leitor buscando levá-lo a agir de determinada maneira. 
Em um curso, o conteúdo deve ser claro e objetivo, para garantir que o receptor da informação irá compreendê-la de forma adequada. Para que isso seja possível, além do teor do conteúdo, é preciso que seu design favoreça sua compreensão. Porém, considerando que o aprendizado segue o ciclo de quatro etapas proposto por David A. Kolb (1976) em sua perspectiva construtivista, o professor possui o papel fundamental de prover aos alunos a experiência concreta e reflexão necessárias para garantir que irão conseguir fazer as correlações necessárias com o conteúdo teórico para melhor compreendê-lo e aplicá-lo. Mas como fazer isso em cursos autoinstrucionais, isto é, que não contam com o suporte de um professor?

Vamos analisar um estudo empreendido por Solvie e Kloek (2007) em que, considerando o ciclo de aprendizagem conforme proposto por David A. Kolb (1976), propuseram fazer um curso de treinamento de métodos de ensino a professores utilizando a tecnologia, sem o auxílio de um orientador. Para criar experiências concretas, foram utilizados áudios e vídeos clipes sobre experiências com diversos modelos de ensino e era esperado que os professores fizessem conexões com conhecimentos prévios, inclusive com seu próprio desenvolvimento de alfabetização, e assim fomentar discussões entre eles e a reflexão os métodos. Para colaborar com a conceituação abstrata, eram disponibilizados aos professores em ambientes virtuais materiais teóricos sobre os quais podiam associar as experiências e reflexões ao conhecimento teórico sobre os modelos e, assim, poderem, em seguida, aplicar esse conhecimento em seus métodos de ensino, como na elaboração de planos de aula ou atividades para os alunos.

Outro método utilizado para desenvolver o design do conteúdo é o baseado no nível do aluno. Jeong e Kim (2009) defendem que o aprendizado deve se adequar às habilidades dos alunos e que os métodos de desenvolvimento de conteúdos de aprendizagem devem se ajustar aos níveis de cada estudante. Para os autores, um conteúdo de qualidade está diretamente relacionado à construção de níveis de dificuldade e dos objetivos de aprendizagem a serem alcançados com base nos conteúdos das tarefas e nas condições de aprendizagem e do ambiente.

Jeong e Kim (2009) ainda criticam a inserção de games e simulações em conteúdos educacionais digitais como forma de induzir o interesse dos alunos, pois isso não muda o caráter unidirecional do conteúdo e sua não consideração do nível do aluno. Para os autores, o conteúdo deve ser desenhado respeitando os níveis dos alunos, e assim a disponibilização e a forma do 
conteúdo dependerá da avaliação do nível do aluno a partir de tarefas anteriores, dessa forma controlando o progresso da aprendizagem de acordo com as diferenças de cada aluno.

É possível perceber, portanto, que a forma como o conteúdo é transmitido faz diferença no aprendizado e, portanto, deve ser levado em consideração no momento de desenvolver conteúdos de cursos autoinstrucionais online, principalmente. Afify (2018) corrobora com essa afirmação, mas defende a utilização de mapas conceituais digitais para o desenvolvimento de conteúdos em cursos online, de forma a garantir o melhor gerenciamento da informação por parte dos alunos.

[...] muitas pesquisas argumentam que os mapas conceituais digitais atenderam às necessidades dos alunos e da equipe de professores ao organizar o conteúdo de materiais digitais. [...] Além disso, eles fornecem aos alunos um método que os ajuda a construir trilhas óbvias através de fontes ligadas no mapa conceitual e controlar a sequência organizando as fontes de aprendizado. Além disso, mapas conceituais fornecem uma interface flexível de acesso ao conteúdo e facilitam o acesso ao conteúdo digital sem esgotar a memória operacional do aluno (Afify, 2018, p. 5 e 6, tradução nossa)

Segundo Novak (1998 apud Afify, 2018), o desenvolvimento de mapas conceituais para o design e a produção de conteúdos também baseia-se em uma perspectiva construtivista, já que a ideia é permitir que os alunos organizem e reformulem o conhecimento por conta própria e os representem a partir das atividades propostas, sem a ajuda do professor.

De forma geral, Afify (2018) afirma que mapas conceituais são ferramentas gráficas utilizadas de organizar e representar a informação de forma visual, utilizando qualquer formato de conteúdo (textos, imagens, vídeos, áudios etc.) e recursos de interatividade, criando hierarquias, conexões e relações que devem guiar o leitor a atingir, a partir de suas próprias capacidades e na sua velocidade, um objetivo previamente estabelecido.

Para isso, o primeiro passo é compreender qual problema o designer do conteúdo deseja-se resolver, isto é, o que se espera que o aluno aprenda ao final do curso. Com base nisso, o conteúdo deve ser desenhado de forma a conduzi-lo até atingir o objetivo final do curso, sem que perca seu interesse ou atenção no decorrer do caminho.

Estudos e pesquisas relevantes para o desenvolvimento do conteúdo de E-learning verificaram a necessidade de desenvolver novos acessos, estratégias, métodos e ferramentas que desenvolvam conteúdos eletrônicos essenciais para diversos ambientes de EAD. (Afify, 2018, p. 8, tradução nossa).

É nesse aspecto que a utilização de nudges pode ser eficiente, pois sua implantação é geralmente fácil e barata e esses elementos ajudam a guiar o comportamento do leitor de maneira 
previsível, mas sem impedi-lo de escolher outra opção de caminho caso julgue interessante e necessário.

\section{O NUDGE NO DESIGN DE CONTEÚDO DE CURSOS AUTOINSTRUCIONAIS}

O nudge é um elemento que está intimamente relacionado ao conhecimento, que é trazido para refazer o caminho da escolha do usuário e incentivá-lo a uma nova tomada de de decisão, que é criada pela Arquitetura da Escolha. Segundo Thaler:

Um arquiteto de escolhas tem a responsabilidade de organizar o contexto no qual as pessoas tomam decisões. (...) Se você faz a cédula de votação usada para escolher candidatos, você é um arquiteto de escolhas. Se você é médico e vai explicar as opções de tratamentos disponíveis para um paciente, você é um arquiteto de escolhas (Thaler, 2019, p.11)".

O nudge é o "empurrãozinho" que irá ajudar para que um item seja escolhido e não o outro. É uma estrutura valiosa para mudar a arquitetura de escolha dos indivíduos, sendo que um dos pressupostos é ter um custo baixo e um alto impacto. É, por isso, que o nudge auxilia no processo da construção do conhecimento e na solução de problemas (a solução enquanto resposta que obteve êxito já pode ser vista como um novo conhecimento), na promoção de aprendizagens e na interação com o contexto onde está inserido.

O nudge é, portanto, uma atividade geradora de conhecimento, já que adiciona valor e permite a busca de soluções criativas. Só que nem sempre ele é identificado por quem o cria. Quando isso acontece, um novo conhecimento pode ser gerado - inclusive dentro do ambiente organizacional. Neste caso, no ambiente de trabalho, por parte dos empregados, quando há um aperfeiçoamento constante dos processos de produção, a integração de novas técnicas e metodologias, a experimentação e a importação de know-how (Nonaka \& Takeuchi, 2004). A busca de soluções criativas só é possível em um contexto onde o indivíduo vive a história como um dos protagonistas e pode assim interferir no seu fluxo tornando o processo de aprendizagem e a produção de conhecimento possível, mesmo que para tal intento seja necessário criar condições para o fomento das escolhas as serem realizadas.

A criação dos ambientes e artefatos que exploram nudge não é fruto de uma única área, mas exige o envolvimento de diferentes profissionais e saberes, tais como pedagogia, designer instrucional, psicologia, artes, tecnologia da informação e comunicação, entre outras. Em tal espaço 
os caminhos a serem trilhados pelos indivíduos nem sempre são os mesmos, pois cada um segue uma dinâmica própria. Uma abordagem interdisciplinar favorece o desenvolvimento das diferentes escolhas, da criatividade e a pluralidade de respostas, possibilitando variados olhares para um mesmo fato ou contexto.

O pensar como em um tabuleiro de opções, mas de forma cuidadosa, com a intenção de se resolver problemas e encorajar a aprendizagem, usando para isso, todos os elementos que possam dar um "empurrãozinho" de maneira apropriada à prática determinada. Também é necessário realizar uma abordagem interdisciplinar considerando a possibilidade das relações existentes entre os diversos campos de conhecimento contribuírem para uma visão mais ampla da realidade e para a busca de soluções significativas aos problemas enfrentados pelos sujeitos, contextualizando os conteúdos frente às exigências de uma sociedade democrática. Levantando questões, abrindo pista, intervindo construtivamente na realidade, favorecendo o pensar antes, durante e depois da ação e, consequentemente, na construção da autonomia intelectual (Cordeiro \& Silva, 2005, p. 18).

Os ambientes virtuais de aprendizagem, por meio de mídias interativas como os nudges, possibilitam uma maior conexão entre indivíduos e máquinas. A disposição de plataformas como mera forma de repositório de conteúdos não é suficiente para dar respostas às indagações atuais. "A interatividade é o ponto chave nesta nova era, focando, principalmente, a participação ativa dos usuários" (Bieging, P., \& Busarello, R. I, 2004, p.7)

As novas tecnologias interativas modificam a natureza da mensagem, o papel do emissor e a relação do usuário (receptor) com a imagem, com o texto, com o conhecimento.

Quanto ao emissor, este assemelha-se ao próprio designer de software interativo: ele constrói uma rede (não uma rota) e define um conjunto de territórios abertos a navegação e dispostos a interferências e modificações, vindas da parte do receptor. Este, por sua vez, torna-se 'utilizador', 'usuário' que manipula a mensagem como co-autor, co-criador, verdadeiro conceptor. (Silva, 2007. p. 11)

Os receptores tornaram-se incapazes de acompanhar argumentos lineares. A vida social do dia a dia remete a tomada de decisões constantes. Orientar essa tomada de decisão em ambientes virtuais de aprendizagem poderá propiciar um maior engajamento por parte do indivíduo na busca do conhecimento.

Os mecanismos de nudges procuram alinhar os interesses dos criadores dos artefatos e objetos com as motivações dos usuários. Neste aspecto, os elementos que contribuem para a 
motivação do indivíduo são identificados como intrínsecos e extrínsecos (Busarelo, 2016). O desafio que se coloca na criação de ambientes e artefatos que exploram a tal perspectiva é saber como estimular efetivamente as duas formas de motivação. Daí a necessidade de um trabalho em conjunto entre as diferentes áreas de conhecimento como psicologia educacional, pedagogia, designer instrucional/educacional, TICs, entre outras.

O uso de nudges, embora esteja relativamente no início no campo da educação e necessite de mais estudos, apresenta-se como um grande aliado no aumento do engajamento e da motivação dos alunos de cursos presenciais e online.

Ocorre uma transposição das aulas do modelo tradicional para o modelo online ou ambientes virtuais, utilizando as tecnologias digitais sem modificar a sua essência de transmissão do conteúdo de um (professor) para muitos (alunos). Mudança cultural requer tempo e espaço de experimentação e de reflexão. Nesse sentido, propostas de integração das metodologias ativas, sempre que possível apoiadas em mídias do conhecimento, apresenta-se como forma de oferecer diferentes experiências de aprendizagem, são consideradas estratégicas adequadas para lidar com esses desafios. Entretanto, "precisamos pensar na integração das tecnologias digitais de forma criativa e crítica, permitindo que elas possam ser usadas em todo o seu potencial, oportunizando aos alunos um ensino mais personalizado, significativo e colaborativo" (Bacich, 2017, p.39).

\section{O USO DE NUDGES NO DUOLINGO}

O desenvolvimento acelerado da tecnologia aliado às mudanças no comportamento do consumidor na busca por mais capacitação e qualificação, principalmente de idiomas, levou a um aumento de disponibilidade de cursos online de idiomas. Um desses cursos é o oferecido pelo aplicativo Duolingo, com mais de 7,7 milhões de downloads na loja de aplicativos do Google. O Duolingo utiliza como estratégia o uso de nudges para prender a atenção do aluno e incentivá-lo a permanecer no curso.

Logo no cadastro, o aplicativo já começa a apresentar vários nudges para auxiliar o usuário. O primeiro é pré-marcar a meta de tempo de estudo que o usuário deve escolher. Independente da motivação dos administradores do aplicativo, com uma opção pré-marcada, o usuário recebe um "empurrão" para escolher esta meta, não tendo que investir muito tempo e 
esforço para tomar esta decisão. Como Thaler (2019) propõe, a organização e as informações dos elementos na tela ajudam o usuário a escolher a melhor opção para si.

Ter uma meta escolhida é importante por dois fatores. O primeiro para que o aplicativo possa ter argumentos para engajar o usuário no futuro, utilizando o argumento de batimento de meta na comunicação do aplicativo para incentivar o usuário a prosseguir em seus estudos. $\mathrm{O}$ segundo, pois conversa com o que afirmam Jeong e Kim (2009), de que o aprendizado deve se ajustar às habilidades ao nível dos alunos. Além disso, já neste momento o Duolingo pede acesso às notificações do aparelho do usuário, trazendo uma comunicação relacionada. Esse elemento, juntamente com a escolha de meta feita pelo usuário, busca auxiliar o aluno a cumprir sua meta de estudos e manter o engajamento com o aplicativo.

Figura 1: Nudges no cadastro do Duolingo

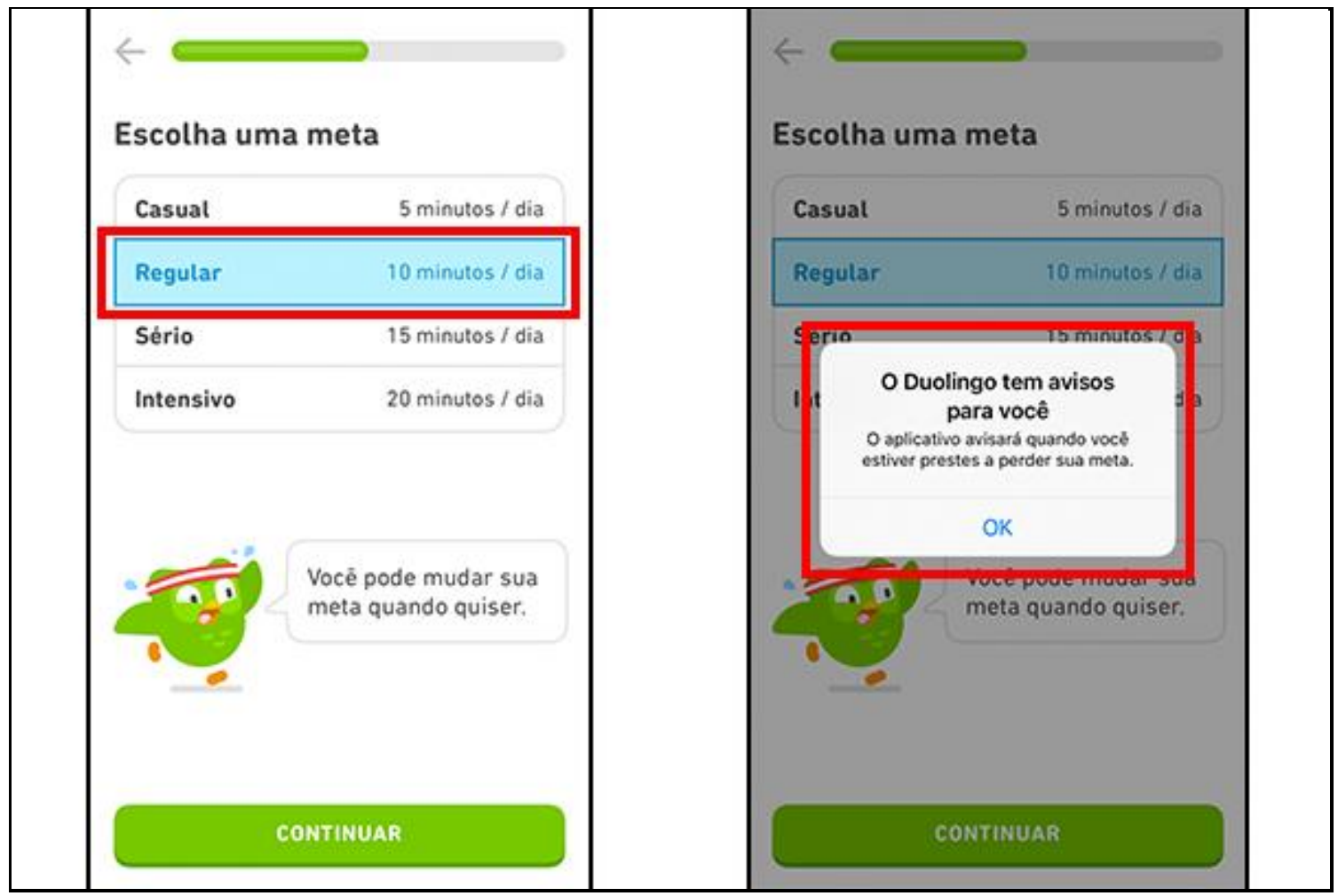

Fonte: Banco de dados dos autores (2019)

Outro nudge utilizado pelo aplicativo é o que busca evitar que o usuário saia sem terminar a lição que começou. Com uma notificação via pop-up o aplicativo informa que o usuário perderá todo o seu progresso caso desista naquele ponto e o obriga a confirmar que quer fazer isso. Essa 
notificação dentro do próprio aplicativo, de baixo custo para os administradores, é uma forma simples de fazer o usuário refletir se vale a pena abandonar seu progresso no meio e motivá-lo a continuar seu aprendizado do idioma.

Um importante nudge utilizado pelo aplicativo são as notificações no celular, que avisam o usuário sobre as lições que faltam ser finalizadas, porém utilizando na comunicação seu avanço nos objetivos diários e semanais. As notificações via push, isto é, aquelas que são enviadas para o celular do usuário, servem para avisar o usuário sobre determinado assunto e ajudá-lo a tomar uma decisão mais rapidamente. Com isso, o usuário poderá ser lembrado das lições que precisa finalizar e seu avanço no aprendizado.

Além das notificações, o aplicativo possui uma ferramenta de comparação do progresso do usuário com seus amigos, para criar um espírito saudável de competição e assim incentivar o usuário a manter o engajamento no aplicativo e continuar evoluindo no aprendizado de uma nova língua. Essa ferramenta apresenta ao aluno de forma interativa (Silva, 2007) seu nível de aprendizagem (Jeong e Kim, 2009), dando mais um incentivo para que continue o progresso dos seus estudos.

Figura 2: Nudges nas notificações do Duolingo

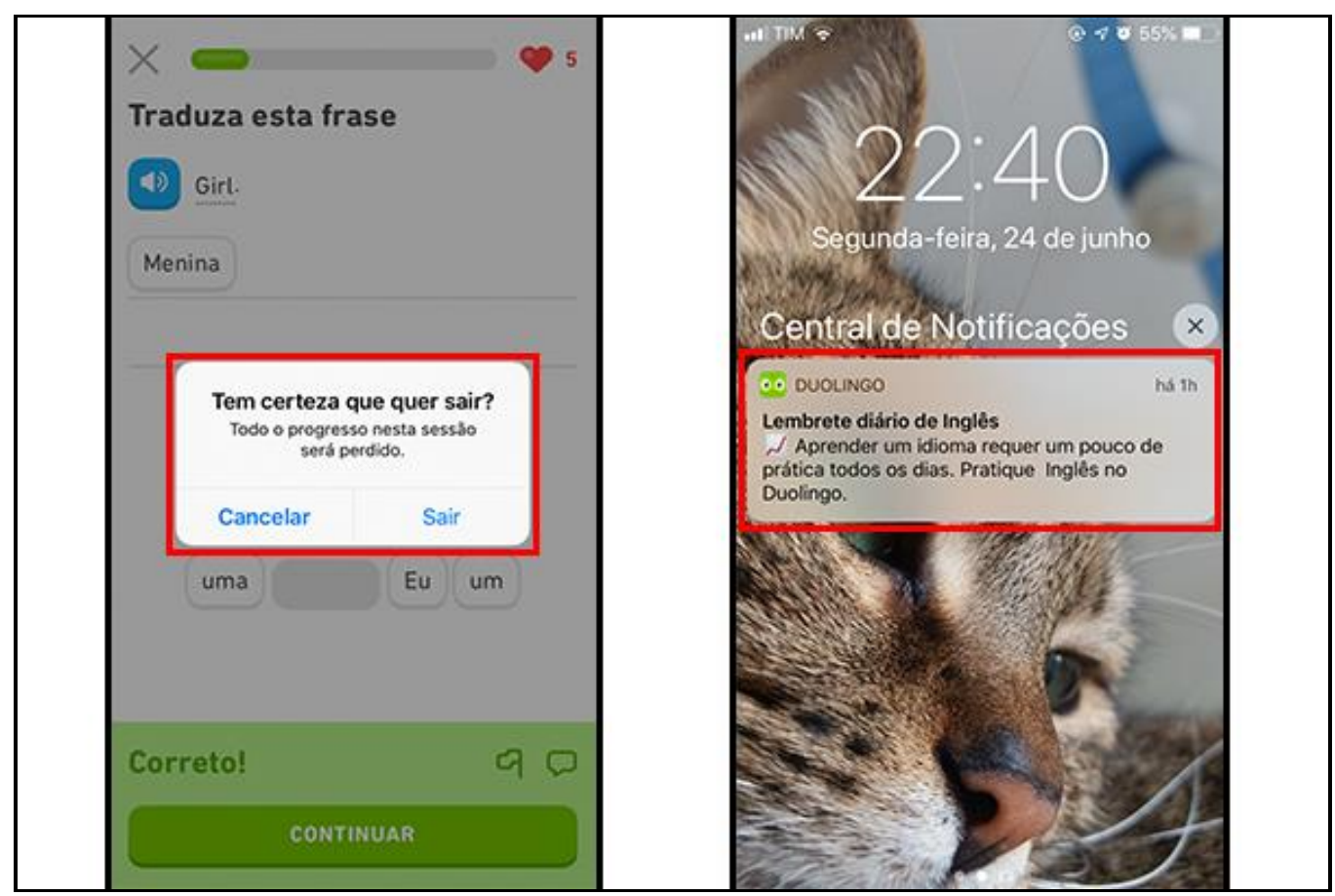

Fonte: Banco de dados dos autores (2019) 
O aplicativo utiliza diversos elementos de "empurrão" para ajudar o usuário a manter seu engajamento no processo de aprendizagem. Um desses elementos é indicar, após o final de cada lição, o quanto o usuário precisa completar para finalizar seu objetivo diário e dá a ele um botão para continuar. Além disso, o aplicativo oferece emblemas, badges e medalhas como formas de incentivo ao usuário. Esses elementos são formas de premiação pelo usuário manter-se engajado no aplicativo e ter evoluído em seu aprendizado.

A partir desses levantamentos foi possível identificar a utilização, em diversos momentos, do uso de nudges no design do conteúdo do aplicativo do Duolingo. Este uso inicia desde o cadastro do usuário, demonstrando uma preocupação desde o primeiro uso do aplicativo em prender a atenção do usuário e mantê-lo engajado até que ele experimente o real valor do aplicativo, que é reconhecer que está aprendendo.

Ao longo da jornada de aprendizado do usuário, é possível também notar o uso de diversos elementos com função de nudge. Esses elementos têm a função de manter os usuários engajados e para incentivá-los a voltarem com determinada frequência a usarem o aplicativo e concluírem suas lições.

Figura 3: Nudges nas recompensas do Duolingo

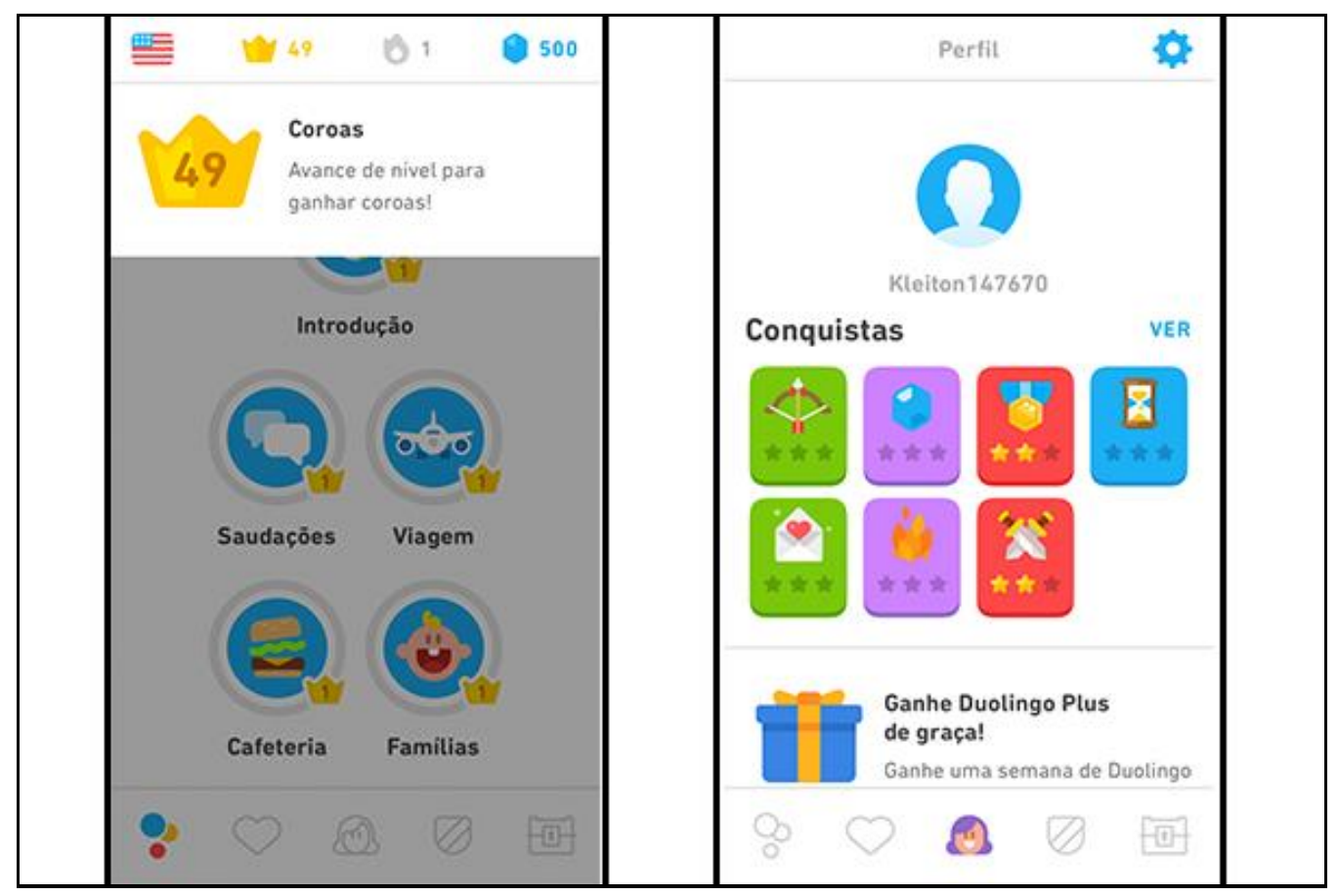

Fonte: Banco de dados dos autores (2019) 


\section{CONSIDERAÇÕES FINAIS}

Com as novas tecnologias e a enxurrada de informações é necessário o desenvolvimento de técnicas que possam prender a atenção e ao mesmo tempo tenham a capacidade de motivar o aluno dentro do ambiente de aprendizagem virtual. Sem essa relação de interação é quase impossível um curso autoinstrucional ter um desempenho satisfatório. É por isso que o presente trabalho procurou abriu caminhos para entender como o uso de nudges pode ajudar a construir um caminho mais favorável ao usuário pelo ambiente EAD.

A revolução da educação está acontecendo todos os dias, formas variadas de passar o conhecimento são apresentadas através do uso de diversas ferramentas e dentro desse contexto o uso dos nudges e da arquitetura da escolha traz a possibilidade de compreender o comportamento do usuário e estimulá-lo a uma melhor aprendizagem.

Neste trabalho, apesar de conseguirmos identificar com clareza o uso de diversos elementos que funcionam como nudges no aplicativo Duolingo, não foi possível aferir a eficiência do uso desses elementos no design do conteúdo do aplicativo do Duolingo e nem promover comparações com aplicativos semelhantes, ficando esse desafio para trabalhos futuros.

\section{REFERÊNCIAS}

Afify, Mohammed (2018, Março). E-learning content design standards based on interactive digital concepts maps in light of meaningful learning theory and constructivist learning theory. Journal of Technology and Science Education, [S.1.], v. 8, n. 1, p. 5-16. Retirado de http://www.jotse.org/index.php/jotse/article/view/267.

Bacich, Lilian (2017). Desafios e possibilidades de integração das tecnologias digitais. Revista Pátio, $\mathrm{n}^{\circ}$ 81, p. 37-39. Retirado de https://loja.grupoa.com.br/revista-patio/artigo/13063/desafios-epossibilidades-deintegracao-das-tecnologias-digitais.aspx

Bieging, P., \& Busarello, R. I., et al (2014). Interatividade nas TICs: abordagens sobre mídias digitais e aprendizagem. São Paulo: Pimenta Cultural.

Busarello, R. I. (2016). Gamification: princípios e estratégias. São Paulo: Pimenta Cultural. 
Cordeiro, B. M. P. \& Silva, S. S. (2005). Direitos Humanos: referencial prático para docentes do Ensino Policial. $2^{\mathrm{a}}$ Ed. Brasília: CICV.

Duarte, J. (2014). Entrevista em profundidade. In: Duarte, José; Barros, Antonio. Métodos e técnicas de pesquisa em comunicação. 2. ed. São Paulo: Atlas, 380 p.

Kolb, D. A. (1984). Experiential learning: Experience as the source of learning and development. New Jersey: Prentice-Hall. Retirado de https://www.researchgate.net/profile/David_Kolb/publication/235701029_Experiential_Learning _Experience_As_The_Source_Of_Learning_And_Development/links/00b7d52aa908562f9f0000 00/Experiential-Learning-Experience-As-The-Source-Of-Learning-And-Development.pdf.

Jeong, Hye-Jin, \& Kim, Yong-Sung (2009). E-Learning Content Design and Implementation based on Learners' Levels. $\quad$ Polibits, 39, pp.59-64. Retirado de http://www.cidetec.ipn.mx.com/polibits/2009_39/39_09.pdf.

Thaler, Richard (2019). Nudge. Rio de Janeiro: Objetiva.

Nonaka, I., \& Takeuchi, H (2004). Criação de conhecimento na empresa. Rio de Janeiro: Elsevier Brasil.

Silva, Marco (2007). Sala de aula interativa. Rio de Janeiro: Quartet.

Solvie, P., \& Kleck, Molly (2007). Using Technology Tools to Engage Students with Multiple Learning Styles in a Constructivist Learning Environment. Contemporary Issues in Technology and Teacher Education, 7(2), 7-27. Retirado de https://citejournal.s3.amazonaws.com/wpcontent/uploads/2016/04/v7i2languagearts1.pdf. 